\title{
Parameters Affecting the Sensitivities of Dideoxy Fingerprinting and SSCP
}

\author{
Qiang Liu and Steve S. Sommer
}

Department of Biochemistry and Molecular Biology, Mayo Clinic/Foundation, Rochester, Minnesota 55905

The goals of the present experiments are (1) to improve dideoxy fingerprinting (ddF) and (2) to utilize ddF as a tool to evaluate the relative merits of different conditions for singlestrand conformation polymorphism (SSCP). ddF is performed by electrophoresing one dideoxy termination reaction through a nondenaturing gel. The ddF pattern can be divided into a "dideoxy component" and an "SSCP component." If dideoxy CTP (ddCTP) is utilized for the termination reaction of ddf, the dideoxy component is abnormal when an extra segment is produced by a sequence change that creates an extra $C$ or when a segment is eliminated by a change of $C$ to another base. All subsequent segments produced by the termination reaction constitute the SSCP component that contains the mutation in a nested series of ddCTP termination products. The SSCP component is informative if $\mathbf{a b}$ normal mobility is detected in one or more of the segments. Herein, we utilize 84 different single-base changes in the human factor IX gene to examine the effects of gel matrix, temperature, and different primers on the sensitivity of ddF. The effects of glycerol and cross-linker ratio were examined on fewer mutations. The following conclusions emerge:

1. The sensitivity of the dideoxy component is invariant, but the sensitivity of the SSCP component can vary greatly with gel matrix, temperature, segment size, and sequence context.

2. For a given segment containing a mutation, it is likely that a mobility shift will be seen under some conditions but not under other conditions. By examining the mobility of the SSCP component in $>2200$ segments, it was found that some conditions are statistically more likely to result in altered mobility, thereby increasing the average sensitivity of mutation detection by ddF or conventional SSCP.

3. GeneAmp and MDE gels are superior to polyacrylamide gels and electrophoresis at $8^{\circ} \mathrm{C}$ is superior to electrophoresis at $23^{\circ} \mathrm{C}$. GeneAmp at $8^{\circ} \mathrm{C}$ provided the highest SSCP component efficiency of all conditions tested; all 84 hemizygotes and $\mathbf{4 0}$ heterozygotes were detected readily by ddF under these conditions.

4. The segments that terminate near the mutation site are likely to show an abnormal mobility on polyacrylamide gels at $23^{\circ} \mathrm{C}$.

5. The likelihood of mobility shifts decreases with segment size, but sequence context can have a major effect on SSCP component efficiency.

6. The smearing of bands sometimes found on the upper part of the gel, especially at $8^{\circ} \mathrm{C}$, was eliminated by utilizing a loading buffer containing $50 \%$ formamide and 7 м urea.
D ideoxy fingerprinting (ddF) is a hybrid between single-strand conformation polymorphism (SSCP) and Sanger dideoxy sequencing. ${ }^{(1)}$ In ddF, a Sanger sequencing reaction performed with one dideoxy terminator is electrophoresed through a nondenaturing gel. Mutations can be detected as a result of gain or loss of a dideoxy termination segment (dideoxy component) and/or by an alteration in the mobility of at least one of the termination segments that contain the mutation (SSCP component). The number of potentially informative segments in the SSCP component can vary from 1 to $>50$, depending on the location of the mutation. The inherent redundancy of ddF facilitates detection of virtually all mutations. In the initial study, ${ }^{(1)}$ each of 83 single-base changes and one 3-base change were detected. In samples from 40 patients with hemophilia B, 13 regions of the factor IX gene were screened in a blinded manner and the results were compared with the "gold standard" of direct genomic sequencing. All 36 mutations detected by genomic sequencing were also detected by ddF. A second blinded comparison of $\mathrm{ddF}$ and direct genomic sequencing detected 26 of 26 mutations in the p53 gene, a gene with a higher $\mathrm{G}+\mathrm{C}$ content than the factor IX gene (55\% vs. $39 \%$ ) (J.S. Kovach and S.S. Sommer, in prep.).

The initial experiments were performed at room temperature with a $5.6 \%$ polyacrylamide gel in the presence of $10 \%$ glycerol. In $50 \%$ of the 84 human factor IX mutations, more than three segments in the SSCP component showed abnormal mobility (type-A pattern). In some of these samples with a type-A pattern, most of the segments in the SSCP component had an altered mobility. In $45 \%$ of the mutations, only one to three segments of the SSCP compo- 
nent had an abnormal mobility (type-B pattern). Although these changes were unequivocal, some of these could have been missed if the gels were not of good quality or the researcher was not experienced. Finally, four of the mutations (5\%) were detected only by the loss of a segment because of the dideoxy component (type- $C$ pattern). These mutations might well have been missed in heterozygous patients.

To help make ddF a more robust screen in routine practice, we searched for conditions that would increase the percent of type-A patterns and decrease the percent of type-C patterns. In the process of these experiments, we examined the mobility of $>2200$ mutant segments from samples with 84 different mutations. Thus, our data also provide a good estimate of the sensitivity of conventional SSCP, which may well be the most widely used method for mutation screening. The experiments indicate that electrophoresis through GeneAmp gels at $8^{\circ} \mathrm{C}$ is particularly efficient at detecting mutations.

\section{MATERIALS AND METHODS}

\section{Materials}

AmpliTaq was purchased from PerkinElmer Cetus. T7 and SP6 RNA polymerases, AMV reverse transcriptase, and RNAsin were from Promega Biotech. $\left[\gamma_{-}{ }^{32} \mathrm{P}\right]$ ATP was purchased from Amersham. GeneAmp (Perkin-Elmer), MDE (AT Biochem), and acrylamide/bis (BioRad) gel matrices were utilized for the experiments. A methods protocol flow chart is shown in Figure 1.

\section{PCR and Transcription}

PCR was performed from human genomic DNA essentially as described earlier. ${ }^{(4)}$ Briefly, 30 cycles of amplification were performed at $94^{\circ} \mathrm{C}$ for $1 \mathrm{~min}, 50^{\circ} \mathrm{C}$ for $2 \mathrm{~min}$, and $72^{\circ} \mathrm{C}$ for $3 \mathrm{~min}$. The PCR mixture contained a total volume of 25 $\mu \mathrm{l}: 50 \mathrm{~mm} \mathrm{KCl}, 10 \mathrm{~mm}$ Tris- $\mathrm{HCl}$ (pH 8.3), $1.5 \mathrm{~mm}$ or $2.5 \mathrm{~mm} \mathrm{MgCl}_{2}, 200 \mu \mathrm{M}$ of each dNTP, $0.1 \mu \mathrm{M}$ of primer, 0.5 unit of AmpliTaq, and $200 \mathrm{ng}$ of genomic DNA. The PCR and ddF primers are listed in Table 1. A detailed description of the informative oligonucleotide names given in Table 1 is provided in Sarkar et al. ${ }^{(5)}$ As an example, for oligonucleotide $A$,

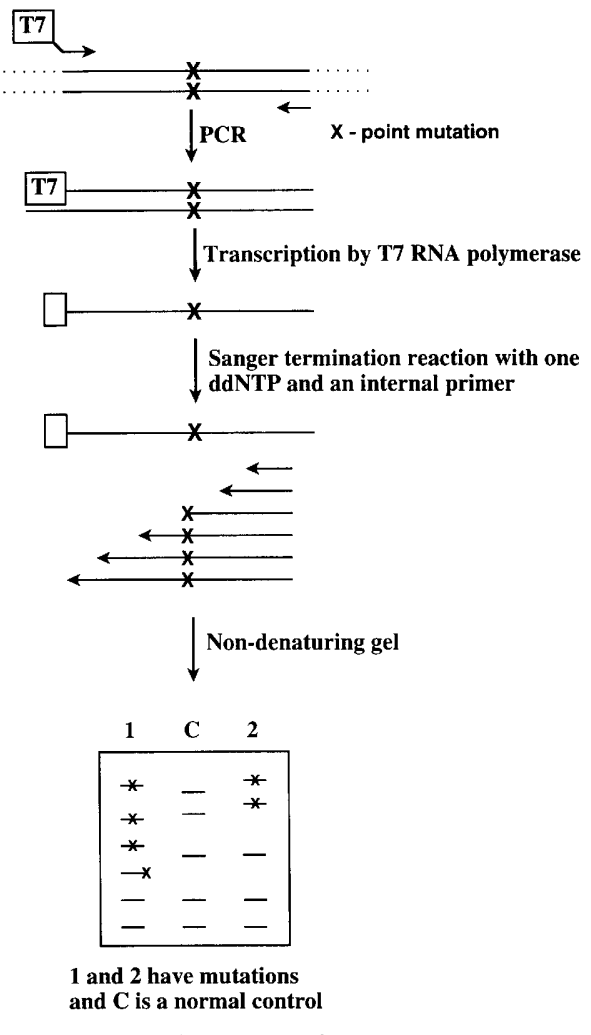

FIGURE 1 Schematic of ddF. ddF may be adapted to any sequencing protocol, because the method involves electrophoresing one lane of a Sanger sequencing reaction on a nondenaturing gel. The protocol utilized in the present experiments is an adaptation of genomic amplification with transcript sequencing (GAWTS). ${ }^{(2,3)}$ At least one of the PCR primers has a 23 -nucleotide phage promoter sequence attached. In the example shown, the amplified region contains a mutation relative to the normal control. The amplified product is transcribed by T7 RNA polymerase, and a Sanger termination reaction is performed with a terminator such as dideoxy CTP. Because the termination reaction primer is nested and end labeled, spurious amplification products do not produce a signal on the autoradiograph. After the termination reaction, the sample is loaded onto a nondenaturing gel and electrophoresed next to a normal control on a nondenaturing gel $(\mathrm{C})$. In the example shown, an extra segment is produced so that the dideoxy component of ddF is informative, for example, the mutation is $\mathrm{A}, \mathrm{T}$, or $\mathrm{G} \rightarrow \mathrm{C}$, and dideoxy CTP is the terminator. In addition, the SSCP component of ddF is also informative (see lane 1 relative to control). In lane 2 , a different mutation is shown. In this case, the dideoxy component is noninformative but the SSCP component is informative. From the ddF pattern, the mutation in lane 2 is highly likely to have occurred at the $3^{\prime}$ end of the mutation in lane 1 .

F9 = factor IX; $($ T7-29) $=29$ bases of the T7 phage promoter sequence; E2(6247)-
$47 \mathrm{D}=5^{\prime}$ end of the oligonucleotide of factor IX-specific sequence begins in exon 2 (E2) at base 6247 (numbering as described in Yoshitake et al. ${ }^{(6)}$ ), and the total length of the oligonucleotide is 47 bases "downstream" (D) (i.e., in the direction of transcription). The precise sizes and locations of the amplified seg. ments and the base pairs screened with ddF can be determined from the informative names.

The $\mathrm{T} 7$ promoter sequence is either 23 bases (TAATACGACTCACTATA GGGAGA) or 29 bases (ggtaacTAATACGACTCACTATAGGGAGA; the lowercase letters are restriction sites and other nonessential sequences). The SP6 promoter sequence is either 23 bases (ATTTAGGTGACACTATAGAATAC), 29 bases (ggtaccATTTAGGTGACACTATAGAATAC), or 35 bases (catacacatacgATTTAGGTGACACTATAGAATAC).

Primers A and B amplify a 630-bp segment containing exons 2 and 3 of the factor IX gene; primers D and E amplify a 359-bp segment of exon 8 of the factor IX gene; and primers I and J amplify a 787-bp segment of the D1 dopamine receptor gene. All of the PCR products contain a T7 promoter sequence at the 5' end and an SP6 promoter sequence at the 3 ' end.

Transcription was performed with 8 units of either T7 or SP6 RNA polymerases (Promega Biotech) in a $20-\mu l$ reaction containing $40 \mathrm{~mm}$ Tris- $\mathrm{HCl}(\mathrm{pH}$ 7.5), $6 \mathrm{mM} \mathrm{MgCl}_{2}, 2 \mathrm{~mm}$ spermidine, 10 $\mathrm{mm} \mathrm{NaCl}, 0.5 \mathrm{~mm}$ each of the four ribonucleoside triphosphates, 32 units of RNAsin (Promega Biotech), and $3 \mu$ of the PCR-amplified template. The transcription reaction was incubated at $37^{\circ} \mathrm{C}$ for $2 \mathrm{hr}$.

\section{Sanger Dideoxy Termination Reaction With One ddNTP}

One pmole of ${ }^{32} \mathrm{P}$-end-labeled primer ( 1 $\mu \mathrm{l}), 1$ or $2 \mu \mathrm{l}$ of template RNA, and $10 \mu \mathrm{l}$ of annealing buffer [250 $\mathrm{mM} \mathrm{KCl}, 10 \mathrm{~mm}$ Tris- $\mathrm{HCl}$ ( $\mathrm{pH} \mathrm{8.3)]} \mathrm{were} \mathrm{mixed.} \mathrm{The} \mathrm{mix-}$ ture was heated at $80^{\circ} \mathrm{C}$ for $3 \mathrm{~min}$ and incubated at $45^{\circ} \mathrm{C}$ for $45 \mathrm{~min}$. Of this mixture, 1 or $2 \mu \mathrm{l}$ was added to $3.3 \mu \mathrm{l}$ of reverse transcription buffer [ $24 \mathrm{~mm}$ Tris$\mathrm{HCl}$ ( $\mathrm{pH} 8.3$ ), $16 \mathrm{~mm} \mathrm{MgCl}_{2}, 8 \mathrm{~mm}$ DTT, $0.8 \mathrm{~mm}$ dATP, $0.4 \mathrm{~mm}$ dCTP, $0.8 \mathrm{~mm}$ dGTP, $1.2 \mathrm{~mm}$ dTTP, and $100 \mu \mathrm{g} / \mathrm{ml}$ of actinomycin D], $0.8-1.0 \mu \mathrm{l}$ of ddNTP (0.25 mM ddCTP, $1.0 \mathrm{~mm}$ ddGTP, or 1.0 mM ddTTP) and 1 unit of AMV reverse 
TABLE 1. Oligonucleotides Used in this Study

\begin{tabular}{llll}
\hline A. & F9-(T7-29)12(6247)-47D & T7 + GACTTTCTTAAGAGATGT & 5' PCR \\
B. & F9-(SP6-29)I3(6818)-45U & SP6 + GATCTTTCTGAGTCCT & $3^{\prime}$ PCR \\
C. & F9-E2(6535)-17U & CTATTCTATGCTCTGCA & ddF \\
D. & F9-(T7-29)E8(30883)-45D & T7 + TCCTCACCACAACTAC & $5^{\prime}$ PCR \\
E. & F9-(SP6-35)E8(31177)-50U & SP6 + GCCAGCACAGAACAT & $3^{\prime}$ PCR \\
F. & F9-(T7-6)E8(30883)-22D & GGGAGATCCTCACCACAACTAC & ddF \\
G. & F9-E8(31101)-17U & CTAAGGTACTGAAGAAC & ddF \\
H. & F9-(SP6-6)E8(31177)-21U & GAATACGCCAGCACAGAACAT & ddF \\
I. & D1-(T7-23)E2(912)-39D & T7 + GCCCTTCTGCATTGAT & 5' PCR \\
J. & D1-(SP6-23)E2(1655)-40U & SP6 + CTGTTCACTGTTGATTC & $3^{\prime}$ PCR \\
K. & D1-E2(1373)-15U & ATGAGCATGTGTGGC & ddF \\
\hline
\end{tabular}

transcriptase. The Sanger sequence mixture was incubated at $55^{\circ} \mathrm{C}$ for $45 \mathrm{~min}$. In initial experiments on ddF sensitivity, 2 $\mu l$ of the Sanger sequence mixture was added to $50 \mu \mathrm{l}$ of stop/loading buffer (40\% formamide, 5 mM EDTA, and $0.5 \%$ each of xylene cyanol and bromphenol blue) to lower the amount of sample loaded on the low-temperature gel, thereby avoiding the smearing that may otherwise occur. The sample was boiled for $3 \mathrm{~min}$, quick-cooled on ice water, and loaded rapidly onto the gel. Ten microliters of stop/loading buffer was added to $2 \mu \mathrm{l}$ of the Sanger termination reaction, as the introduction of stop/loading buffer mainly containing $50 \%$ formamide/7 $\mathrm{M}$ urea/2 mM EDTA ( $5 \mathrm{ml}$ formamide, 4.2 grams of urea, $1.5 \mathrm{ml}$ of $20 \mathrm{~mm}$ EDTA), or $50 \%$ formamide $/ 7 \mathrm{~m}$ urea $/ 10$ mM $\mathrm{NaOH}$ is used to prevent the smearing. The new samples were heated for 5 min at $80^{\circ} \mathrm{C}$, quick chilled, and loaded immediately onto the gel. Although much less of the improved stop/loading buffer is used, clear autoradiography without smearing is obtained routinely.

\section{ddF Electrophoresis}

The sample $(1.5 \mu \mathrm{l})$ was loaded into square wells (shark-tooth combs resulted in interactions at lane boundaries). Electrophoresis of $7.5 \%$ GeneAmp, $0.5 \times$ MDE (fourfold dilutions of the stock solutions provided by the supplier), and $5.6 \%$ polyacrylamide gels $(45 \mathrm{~cm} \times 37.5$ $\mathrm{cm} \times 0.35 \mathrm{~mm}$ ) was performed with 50 $\mathrm{mm}$ Tris-borate ( $\mathrm{pH} \mathrm{8.3)} \mathrm{and} 1 \mathrm{~mm}$ EDTA at $12 \mathrm{~W}$ constant power using a Poker Face SE 1500 sequencing apparatus. For low-temperature gels, electrophoresis was performed in a cold room $\left(2-3^{\circ} \mathrm{C}\right)$ with a fan directly cooling the plate to keep it at $7-8^{\circ} \mathrm{C}$. Temperature was measured by either a liquid crystal thermometer (accuracy $\pm 3^{\circ} \mathrm{C}$ ) placed on the outer plate or a mercury thermometer placed in the upper buffer chamber. Both measurements were similar. For electrophoresis at room temperature, the temperature was regulated by circulating water to keep the electrophoresis plates at $22-24^{\circ} \mathrm{C}$. After an initial electrophoresis for $15-30 \mathrm{~min}, 1.5 \mu \mathrm{l}$ of sample was loaded for $4 \mathrm{hr}$ at low temperature or for $3 \mathrm{hr}$ at room temperature. During the course of electrophoresis, the temperatures varied only by $1-2^{\circ} \mathrm{C}$. The average temperatures of $8^{\circ} \mathrm{C}$ and $23^{\circ} \mathrm{C}$ are utilized throughout these experiments. The gel was dried and subjected to autoradiography.

\section{ddF Analysis}

All segments of the SSCP component were scored by visual analysis for the presence of abnormal mobility in comparison with normal samples. For primers $\mathrm{C}$ and $\mathrm{H}$, a wild-type sample was loaded every three lanes so that a normal sequence always was immediately adjacent. For primers $F$ and $G$, a wild-type sample was located every five lanes. Unequivocal mobility changes were scored. Typically, a mobility change of one-half of a bandwidth or more was necessary for a scored mobility shift. Occasionally, a wild-type band may be composed of two overlapping or partially overlapping segments. If a mutation resolves the two segments into two separate bands, one or two abnormal mobility changes are scored depending on whether there is a band at the position of the wild-type band. Rarely, a single termination segment has two stable states, each of dif- ferent mobility. If a mutation in that segment changes the pattern, one or two mobility changes could be scored.

\section{Efficiency vs. Sensitivity}

The utility of the SSCP component can be quantitated in two ways, which are referred to by the terms efficiency and sensitivity. The efficiency of the SSCP component for a given mutation is the number of abnormally migrating segments divided by the total number of segments in the SSCP component. The average SSCP component efficiency for a region is determined by dividing the number of segments with abnormal mobilities for all of the mutations by all of the segments in the SSCP component. The sensitivity of the SSCP component is the percentage of samples in which the presence of a mutation could be detected, that is, the percent in which the efficiency of the SSCP component is $>0$. The sensitivity of the SSCP component of ddF is different from that of conventional SSCP in which a mobility change in either of two complementary strands is necessary to detect the presence of the mutation. The sensitivity of conventional SSCP can be estimated from the efficiency of the SSCP component of ddF by assuming that the two segments in a conventional SSCP behave independently (see Table 3 footnotes and Results, below). If segments do not behave independently, the observed sensitivity of conventional SSCP should be lower than the estimated value. The sensitivity of ddF is the fraction of mutations that can be detected by either the dideoxy or the SSCP components.

\section{RESULTS}

\section{Effects of Temperature, Gel Matrix, and Cenomic Region}

The bulk of the experiments described below were performed without glycerol, because the addition of glycerol to gels reduces convenience, increases bandwidth, and generates a potential source of variation caused by incomplete mixing (data not shown). Multiple gel matrices were tested, including three experimental matrices kindly provided by AT Biochem. Of the group, 7.5\% GeneAmp gels and $0.5 \times \mathrm{MDE}$ gels were the most promising matrices. The efficiencies of GeneAmp, MDE, and polyacrylamide 


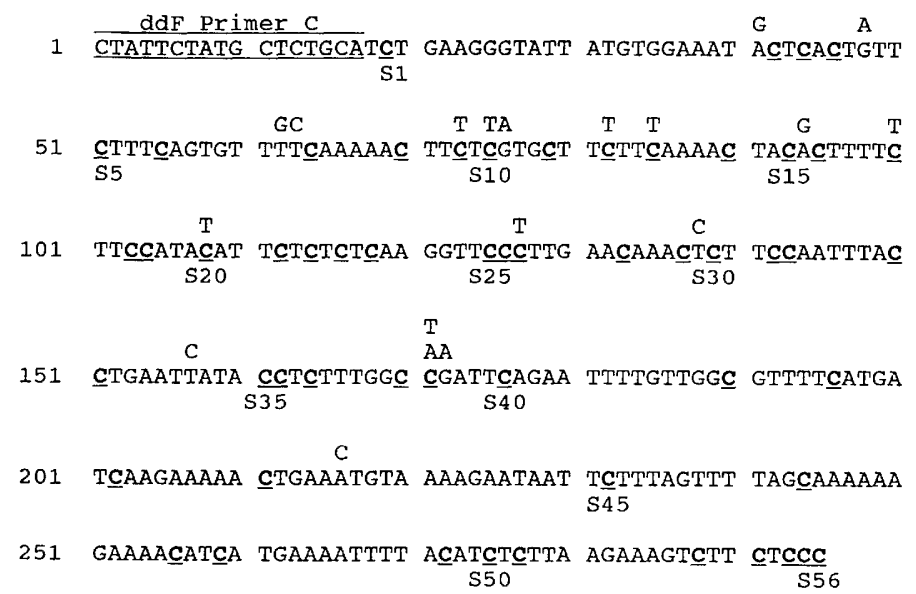

FICURE 2 Screening for mutations in exon B of the factor IX gene. The 5 ' end of the ddF primer $\mathrm{C}$ ( $17 \mathrm{bp}$, underlined) corresponds with the first nucleotide of the sequence. Nineteen single-base substitutions are shown above the normal sequence. The termination products produced by the ddCTP Sanger reaction are underlined and numbered consecutively (S1-S56). Segments 2-56 comprise the ddF patterns shown in Fig. 3. The segments examined have a maximum size of $295 \mathrm{bp}$. gels were compared when electrophoresed at $23^{\circ} \mathrm{C}$ and $8^{\circ} \mathrm{C}$.

Eighty-four different single-base mutations in the factor IX gene were exam- ined with four different ddF primers from genomic DNA of 82 males and 2 females with hemophilia B. Most of the mutations in the current sample were
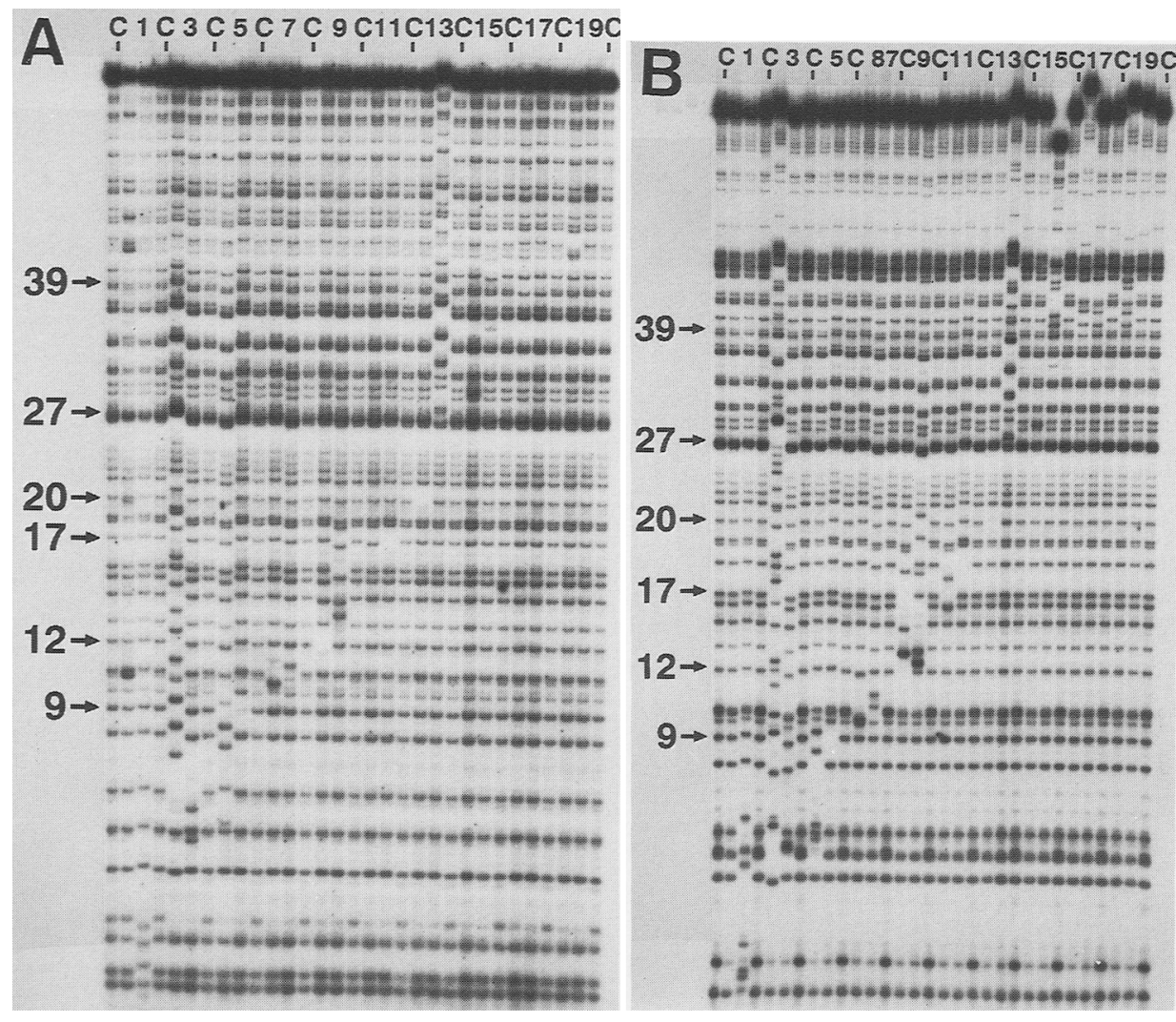

FIGURE 3 Sample ddF gels performed with primer C. Exon B of the human factor IX gene was amplified, transcribed, and reverse transcribed in the presence of ddCTP (see Materials and Methods). The samples were electrophoresed through nondenaturing gels under the following conditions: $(A) 5.6 \%$ polyacrylamide gels at $23^{\circ} \mathrm{C} ;(B) 7.5 \%$ GeneAmp gels at $8^{\circ} \mathrm{C}$. (Lanes $C$ ) Control DNA with wild-type sequence; (lanes 1-19) 19 different point mutations in the order shown in Fig. 2. This region has the lowest efficiency of all the regions examined. The ddGTP termination segments are numbered as in Fig. 2. different from those examined in the initial study. ${ }^{(1)}$ The dideoxy terminator used in most experiments was either ddCTP or ddGTP.

Of the 84 samples examined, 50 had an abnormal dideoxy component. Thirty percent of the these samples had an extra segment whereas $70 \%$ lost one of the segments. The excess of lost segments when using ddCTP or ddGTP reflects the known hot spot of transition mutations at the dinucleotide CpG. All of the expected changes in the dideoxy component were detected under all conditions tested. In contrast, the efficiency of the SSCP component varied dramatically. Sample data are shown (Figs. 2 and 3) and analyzed (Table 2 and Fig. 4) for 19 mutations in the genomic region of lowest efficiency. When the samples were electrophoresed through polyacrylamide gels under standard conditions (see Materials and Methods) at $23^{\circ} \mathrm{C}$, the efficiency of the SSCP component varied for each mutation. Greater than $80 \%$ of the segments in the SSCP component showed altered mobility for three factor IX gene mutations, whereas $<10 \%$ of the segments showed altered mobility in each of the 12 mutations (Table 2). In addition, five mutations showed no alterations in the SSCP component. Thus, the likelihood that a given segment displays altered mobility depends markedly on the particular mutation. When averaged, the SSCP component efficiency was $22.5 \%$ for the 19 mutations analyzed with primer $\mathrm{C}$.

When these 19 samples were electrophoresed through GeneAmp at $8^{\circ} \mathrm{C}$, the average efficiency of the SSCP component increased to $71.4 \%$. A similar increase in the efficiency of the SSCP component was found when ddF was performed with primer $\mathrm{G}$ (Fig. 5). In Figure 5 , lanes 5 and 6 have no signal because the mutations are located in the primer region. This illustrates that a reproducibly poor signal in the presence of adequate transcript template can be caused by a mutation in the sequence complementary to the termination reaction primer.

For the great majority of mutations, the fingerprints generated with the MDE gels were similar to those with the GeneAmp gels. Visual inspection of the autoradiographs indicated that MDE and GeneAmp gels have similar SSCP efficiencies at $23^{\circ} \mathrm{C}$ and $8^{\circ} \mathrm{C}$ for the four primers tested. When quantitation was 
TABLE 2 Analysis of Dideoxy and SSCP Components for Primer C

\begin{tabular}{|c|c|c|c|c|c|c|c|c|}
\hline \multirow[b]{2}{*}{ Number $^{a}$} & \multirow[b]{2}{*}{ Mutation $^{\mathrm{b}}$} & \multirow[b]{2}{*}{$\begin{array}{l}\text { Segment } \\
\text { length }^{c}\end{array}$} & \multirow[b]{2}{*}{$\begin{array}{l}\text { Dideoxy } \\
\text { component }^{\mathrm{d}}\end{array}$} & \multirow{2}{*}{$\begin{array}{l}\text { First } \\
\text { SSCP } \\
(\text { no. })^{\mathbf{e}}\end{array}$} & \multicolumn{4}{|c|}{ SSCP efficiency $(\%)^{\mathrm{f}}$} \\
\hline & & & & & $\begin{array}{l}\mathrm{PA} \text { at } \\
23^{\circ} \mathrm{C}\end{array}$ & $\begin{array}{l}\mathrm{GA} \text { at } \\
23^{\circ} \mathrm{C}\end{array}$ & $\begin{array}{l}\text { PA at } \\
8^{\circ} \mathrm{C}\end{array}$ & $\begin{array}{l}\text { GA at } \\
8^{\circ} \mathrm{C}\end{array}$ \\
\hline 1 & $A \rightarrow G$ & 41 & 0 & 2 & 10.9 & 47.3 & 9.6 & 50.6 \\
\hline 2 & $\mathrm{G} \rightarrow \mathrm{A}$ & 48 & 0 & 5 & 98.1 & 94.2 & 94.2 & 100 \\
\hline 3 & $\mathrm{~T} \rightarrow \mathrm{G}$ & 62 & 0 & 7 & 12.0 & 62.0 & 60.0 & 78.0 \\
\hline 4 & $\mathrm{~T} \rightarrow \mathrm{C}$ & 63 & + & 7 & 84.0 & 86.0 & 8.0 & 26.0 \\
\hline 5 & $\mathrm{C} \rightarrow \mathrm{T}$ & 73 & - & 10 & 0 & 48.9 & 42.6 & 91.5 \\
\hline 6 & $\mathrm{C} \rightarrow \mathrm{T}$ & 75 & - & 11 & 4.3 & 47.8 & 13.0 & 76.1 \\
\hline 7 & $\mathrm{G} \rightarrow \mathrm{A}$ & 76 & 0 & 11 & 4.3 & 78.3 & 6.5 & 82.6 \\
\hline 8 & $\mathrm{C} \rightarrow \mathrm{T}$ & 82 & - & 13 & 6.8 & 65.9 & 36.4 & 22.7 \\
\hline 9 & $\mathrm{C} \rightarrow \mathrm{T}$ & 85 & - & 14 & 16.3 & 14.0 & 60.5 & 95.3 \\
\hline 10 & $A \rightarrow G$ & 94 & 0 & 16 & 4.9 & 2.4 & 70.7 & 34.1 \\
\hline 11 & $\mathrm{C} \rightarrow \mathrm{T}$ & 100 & - & 18 & 0 & 0 & 64.1 & 100 \\
\hline 12 & $\mathrm{C} \rightarrow \mathrm{T}$ & 108 & - & 21 & 0 & 0 & 0 & 100 \\
\hline 13 & $\mathrm{C} \rightarrow \mathrm{T}$ & 127 & - & 28 & 100 & 100 & 100 & 100 \\
\hline 14 & $\mathrm{~T} \rightarrow \mathrm{C}$ & 138 & + & 30 & 0 & 0 & 0 & 7.4 \\
\hline 15 & $\mathrm{~T} \rightarrow \mathrm{C}$ & 157 & + & 35 & 9.1 & 13.6 & 77.2 & 86.4 \\
\hline 16 & $\mathrm{C} \rightarrow \mathrm{A}$ & 171 & - & 40 & 5.9 & 5.9 & 76.5 & 100 \\
\hline 17 & $\mathrm{C} \rightarrow \mathrm{T}$ & 171 & - & 40 & 5.9 & 5.9 & 52.9 & 64.7 \\
\hline 18 & $\mathrm{G} \rightarrow \mathrm{A}$ & 172 & 0 & 40 & 5.9 & 82.4 & 64.7 & 100 \\
\hline 19 & $\mathrm{~A} \rightarrow \mathrm{C}$ & 216 & + & 45 & 0 & 0 & 50.0 & 50.0 \\
\hline Average (\%) & & & $68.4^{\mathrm{g}}$ & & 22.5 & 45.5 & 43.4 & 71.4 \\
\hline
\end{tabular}

${ }^{\text {a Sample number as shown in Fig. } 3 .}$

${ }^{b}$ Mutation present in the reverse-transcribed segments.

'Length (in bp) from the 5 ' end of the segment (see Fig. 2); corresponds to the minimum size termination segment that can contain the mutated base.

${ }^{\mathrm{d} D i d e o x y}$ component. (+) An extra segment is produced; (-) a segment is eliminated; and (0) no change observed. All abnormal dideoxy components were detected under all conditions.

eThe smallest segment of the SSCP component is numbered sequentially as indicated in Fig. 2 . That segment and all subsequent segments comprise the SSCP component.

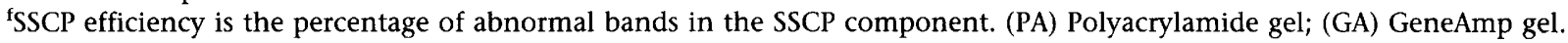

gercent of samples with an informative dideoxy component.

performed for MDE gels electrophoresed at $8^{\circ} \mathrm{C}$, the average SSCP efficiency was slightly lower than with GeneAmp gels ( $77 \%$ vs. $81 \%$ for the 84 mutations). Because quantitation of ddF gels is laborious, only GeneAmp and polyacrylamide gels were chosen for the comprehensive comparisons that follow.

When polyacrylamide and GeneAmp gels at $23^{\circ} \mathrm{C}$ and $8^{\circ} \mathrm{C}$ were compared for primer $\mathrm{C}$, it was found that the SSCP component had a higher efficiency at $8^{\circ} \mathrm{C}$ (Fig. 4). At a given temperature, GeneAmp gels have a higher SSCP efficiency than polyacrylamide gels. This is true in the four regions of the factor IX gene examined (Table 3 ). GeneAmp gels at $8^{\circ} \mathrm{C}$ consistently displayed the highest efficiency. Sample gels from another region of the factor IX gene illustrate the qualitative as well as a quantitative improvement of GeneAmp gels at $8^{\circ} \mathrm{C}$ relative to polyacrylamide gels at $23^{\circ} \mathrm{C}$, that is, the presence of mutations is more fre- quently apparent in the autoradiography (Fig. 5).

The SSCP efficiencies shown are for a nested series of $5^{\prime}$-coterminal strands produced by a Sanger dideoxy termination reaction. In conventional SSCP, a mobility shift in either of two complementary strands is sufficient to detect the mutation. Assuming that complementary strands have approximately independent mobilities, a maximal estimate of the average sensitivity of conventional SSCP can be obtained for a given set of experimental conditions (Table 3 ). Analyses of ddF patterns produced from complementary strands are compatible with the above assumption (data not shown).

The sensitivity of ddF is higher than that of conventional SSCP because a single abnormal segment caused by either the dideoxy or the SSCP component is sufficient to detect the presence of the mutation. The sensitivity of ddF for hemizygous mutations ranged from $92 \%$ for polyacrylamide gels at $23^{\circ} \mathrm{C}$ to $100 \%$ for GeneAmp gels at $8^{\circ} \mathrm{C}$ (Table 4). For heterozygous mutations, the estimated frequency is somewhat lower, ranging from $87-99.6 \%$. In limited experiments with heterozygotes, all 40 different mutations were detected with polyacrylamide and GeneAmp gels at $8^{\circ} \mathrm{C}$. As might be expected, the ddF pattern for the heterozygote was almost always ( $>99 \%$ ) the sum of the patterns for the hemizygote mutant and hemizygote normal individual (data not shown). However, a few examples of anomalous patterns were found that presumably represent interactions of sequence conformers (data not shown).

\section{Distribution of SSCP Efficiencies}

The efficiency of the SSCP component at $23^{\circ} \mathrm{C}$ for most mutations is associated 


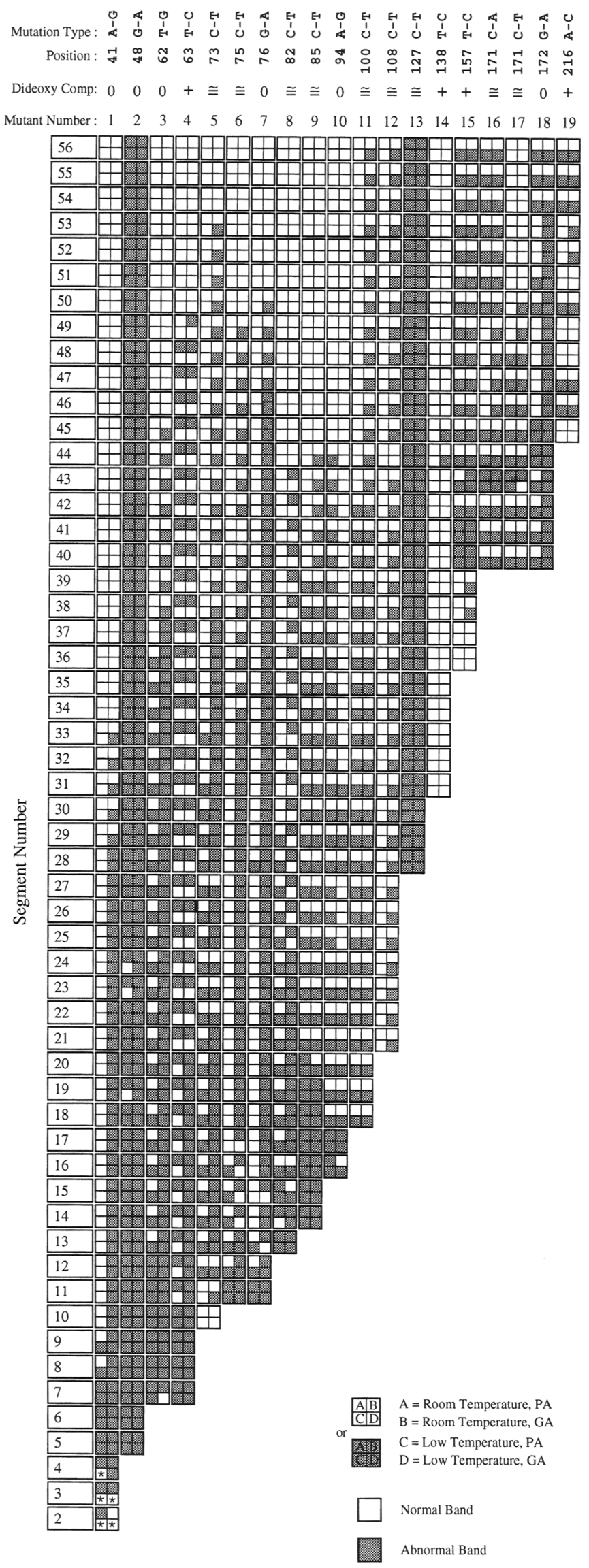

FIGURE 4 Graphic analysis of the SSCP component of ddF performed with polyacrylamide gels at $23^{\circ} \mathrm{C}$ and $8^{\circ} \mathrm{C}$, and GeneAmp gels at $23^{\circ} \mathrm{C}$ and $8^{\circ} \mathrm{C}$. The 19 mutations indicated in Fig. 2 were analyzed. An asterisk $\left({ }^{*}\right)$ indicates that the segment could not be scored because it was electrophoresed out of the gel. The numbers 2-56 correspond with the ddCTP termination segments shown in Fig. 2 . The sequencing change indicates whether the dideoxy component is noninformative $(0)$ or whether an extra $(+)$ or missing (@) band occurred. The sample numbers correspond to the lane numbers in Fig. 3. with either a very high efficiency (81$100 \%)$ or with a low efficiency $(0-20 \%)$. When electrophoresis is performed at $8^{\circ} \mathrm{C}$, mutations associated with very low SSCP efficiency are reduced greatly, especially when the GeneAmp gel matrix is used (Fig. 6A).

When mutations were present in small segments (20-80 bp), the average SSCP efficiency ranged from $68 \%$ in polyacrylamide gels at $23^{\circ} \mathrm{C}$ to $84 \%$ in GeneAmp gels at $8^{\circ} \mathrm{C}$ (Fig. 6B). For polyacrylamide gels at $23^{\circ} \mathrm{C}$, the efficiency fell to $40 \%, 34 \%$, and $8 \%$ for segments of 81-160, 161-240, and 241-295 bp, respectively. In contrast, the SSCP efficiency of GeneAmp gels at $8^{\circ} \mathrm{C}$ did not fall significantly until segments of 241295 bp were examined (Fig. 6B). However, the latter conclusion must be regarded tentatively because the sample size of the SSCP component (293 bands) is derived from only 19 mutations within one genomic region. No simple pattern was discerned when the efficiency of the SSCP component was analyzed by type of mutation (Table 5). In particular, the more bulky changes produced by transversions were not detected more readily than changes produced by transitions.

For polyacrylamide gels at room temperature, the SSCP component efficiency is much higher when the $3^{\prime}$ end of a segment terminates a short distance from the mutation (Table 6). Similar, but less dramatic, effects are seen for samples electrophoresed through polyacrylamide gels at $8^{\circ} \mathrm{C}$ or GeneAmp gels at $23^{\circ} \mathrm{C}$. No such effect is seen for GeneAmp gels at $8^{\circ} \mathrm{C}$. When present, this effect was seen for each of the four genomic regions. The observed gradient may well reflect an intrinsic predisposition toward mobility change when the mutation is near the $3^{\prime}$ end, but the effects of the enlarged segment size and the presence of a terminal dideoxy nucleotide could contribute to the gradient. 

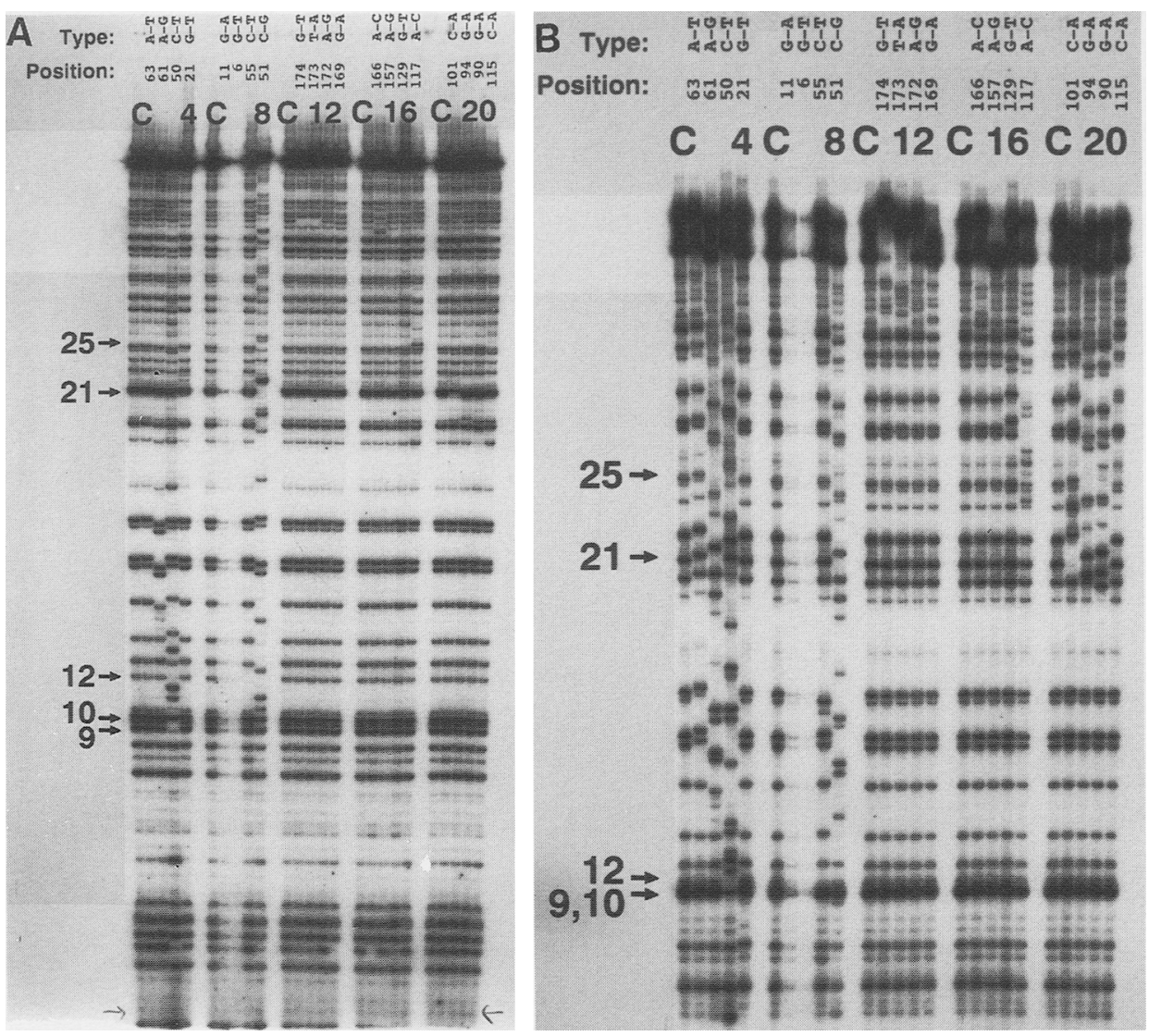

FICURE 5 Additional ddF gels illustrating the better reproducibility of SSCP component efficiency from region to region when samples are electrophoresed through GeneAmp gels at $8^{\circ} \mathrm{C}$. $\mathrm{ddF}$ was performed with primer $\mathrm{G}$ as described in Materials and Methods. The samples were electrophoresed under the following conditions: $(A) 5.6 \%$ polyacrylamide gel at $23^{\circ} \mathrm{C} ;(B) 7.5 \%$ GeneAmp gel at $8^{\circ} \mathrm{C}$. The type of base substitution and their positions are shown on top of the gel.

\section{Other Conditions}

In the previous publication describing $\mathrm{ddF}^{(1)} 100 \%$ of mutations were detected by polyacrylamide gels at $23^{\circ} \mathrm{C}$. In those experiments, glycerol was added to the gels. Because the ddF sensitivity of polyacrylamide gels without glycerol was only $92 \%$, the effect of glycerol on the SSCP component was directly compared in polyacrylamide or MDE gels at $23^{\circ} \mathrm{C}$. Primer $\mathrm{H}$ was utilized for these experiments. For certain individual mutations, glycerol either markedly increased or markedly decreased the SSCP component efficiency. The average SSCP component efficiency with glycerol was somewhat higher than for identical conditions without glycerol ( $56 \%$ vs. $61 \%$ for polyacrylamide gels without and with glycerol, respectively, and $64 \%$ vs. $77 \%$ for MDE gels without and with glycerol).

Polyacrylamide gels with an acryla- mide/bisacrylamide ratio of $50: 1$ are sometimes used for SSCP. When ratios of 19:1 and 50:1 were directly compared using primers $C$ and $F$, the average efficiency of the SSCP component was higher to a variable degree at 50:1, (22\% vs. $46 \%$ for primer $C$, and $34 \%$ vs. $38 \%$ for primer F), but for certain individual mutations the efficiency of the SSCP component was higher at a 19:1 ratio.

Thus, glycerol and a low ratio of cross-linker seem to enhance the average efficiency of the SSCP component of MDE or polyacrylamide gels at room temperature. However, for a given region, the efficiency of GeneAmp gels at $8^{\circ} \mathrm{C}$ was always the highest.

\section{Effects of Stop/Loading Buffer}

The segment of the D1 dopamine receptor gene is chosen for these experiments because the segments in the upper half of the gel were particularly susceptible to smearing when electrophoresis was performed at $8^{\circ} \mathrm{C}$. Twelve types of stop/loading buffers composed of $98 \%$ formamide, $98 \%$ formamide $/ 5 \mathrm{~mm} \mathrm{NaOH}$, $40 \%$ formamide, $40 \%$ formamide $/ 5 \mathrm{~mm}$ $\mathrm{NaOH}, 8 \mathrm{~m}$ urea, $8 \mathrm{~m}$ urea/5 mm NaOH, $50 \%$ formamide $/ 7 \mathrm{M}$ urea, $50 \%$ formamide/7 mm urea/5 mM NaOH, $80 \%$ DMSO $\mathrm{mm}$ (dimethylsulfoxide), $80 \%$ DMSO/5 mM NaOH, 40\% DMSO, and $40 \% \mathrm{DMSO} / 5 \mathrm{~mm} \mathrm{NaOH}$ were screened using $0.5 \times \mathrm{MDE}$ gels at $8^{\circ} \mathrm{C}$ and $23^{\circ} \mathrm{C}$ (data not shown).

The stop/loading buffer composed of $50 \%$ formamide $/ 7 \mathrm{~m}$ urea reproducibly produced the sharpest bands even under the most adverse circumstances, that is, electrophoresis at low temperature with a slow-cooling sample after heat denaturation and the addition of high levels of RNA (Fig. 7). Addition of extra template RNA, complementary RNA, or unrelated RNA to the sequencing reaction caused smearing on MDE gels when $40 \%$ formamide was the stop/loading buffer. The smearing was eliminated by $50 \%$ formamide $/ 7 \mathrm{~m}$ urea stop/loading buffer. The characteristics of the MDE gel suggest that the smearing was caused primarily by hybridization and/or some other intermolecular interaction among nucleic acids before and/or within the electrophoresis. Stop/loading buffer with $50 \%$ formamide $/ 7 \mathrm{~m}$ urea also eliminates smearing when samples are electrophoresed through polyacrylamide gels at $23^{\circ} \mathrm{C}$ (data not shown).

\section{DISCUSSION}

The ddF pattern can be divided into dideoxy component and SSCP component. For random sequence of $50 \%$ $\mathrm{G}+\mathrm{C}, 50 \%$ of samples are expected to have an abnormal dideoxy component no matter which ddNTP is used. Half the time the dideoxy component will be attributable to the presence of an extra band, and half the time attributable to the absence of an extra band. In practice, the frequency of an abnormal dideoxy component is influenced by the types of mutation and the dideoxy nucleotide used. In our sample, 50 of 84 mutations displayed an abnormal dideoxy component $(60 \%)$ when ddCTP and ddGTP were used. Because extra segments are detected more easily with heterozygotes, ddTTP or ddATP is the terminator of choice when mammalian DNA is 
TABLE 3 Efficiency of the SSCP Component Varies with the Region Analyzed

\begin{tabular}{|c|c|c|c|c|c|}
\hline \multirow{2}{*}{$\begin{array}{l}\text { ddF } \\
\text { primer }^{\text {a }}\end{array}$} & \multirow{2}{*}{ 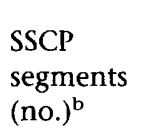 } & \multicolumn{2}{|c|}{$\begin{array}{c}\text { Efficiency at } \\
23^{\circ} \mathrm{C}(\%)^{\mathrm{c}}\end{array}$} & \multicolumn{2}{|c|}{$\begin{array}{c}\text { Efficiency at } \\
8^{\circ} \mathrm{C}(\%)^{\mathrm{c}}\end{array}$} \\
\hline & & PA & GA & PA & GA \\
\hline $\mathrm{C}$ & $687-90$ & 22 & 46 & 43 & 71 \\
\hline F & 518 & 34 & 52 & 52 & 77 \\
\hline G & $314-6$ & 30 & 67 & 76 & 81 \\
\hline $\mathrm{H}$ & $742-6$ & 56 & 64 & 73 & 88 \\
\hline Total sample & $2261-70$ & 38 & 57 & 60 & 81 \\
\hline $\begin{array}{l}\text { Estimated average sensitivity of conven- } \\
\text { tional SSCP of complementary strands }\end{array}$ & & 62 & 82 & 84 & 96 \\
\hline
\end{tabular}

${ }^{a}$ The primers screen exon $\mathrm{B}$ and part of exon $\mathrm{H}$ in the factor IX gene (Materials and Methods). ddCTP was used with primers C, F, and G; ddGTP was used with primer H.

${ }^{b}$ Total number of ddCTP or ddGTP terminated segments in 84 mutations examined that contain a mutation. The numbers vary slightly because one or a few segments electrophoresed completely through the gel matrix. The number of different mutants examined for primers $C, F, G$, and $\mathrm{H}$ were $19,21,18$, and 26 , respectively. The size of the regions scanned was $295,236,221$, and $229 \mathrm{bp}$, respectively (average equals $245 \mathrm{bp}$ ). Up to $56,50,40$, and 51 bands, respectively, were scored for these regions.

'Percentage of all SSCP segments that displayed an altered mobility relative to the corresponding wild-type segments when electrophoresed through PA (polyacrylamide) or GA (GeneAmp) gels, e.g., the total number of segments showing altered mobility divided by the total number of segments containing a mutation in the SSCP component.

${ }^{\mathrm{d}}$ Calculated by assuming that the efficiency of mutation detection in one strand is independent of the mutation in the complementary strand and the average efficiency of the data sample of 84 mutations. Thus, the fraction of mutations in which at least one of the complementary strands show altered mobility on SSCP is $1-(1 \text { - average efficiency of a single strand })^{2}$. For example, for the total sample of polyacrylamide gels at $23^{\circ} \mathrm{C}$, the efficiency is $1-(1-0.38)^{2}=0.62$. screened under conditions in which heterozygotes are expected. This is because $25-33 \%$ of mutations in many genes are caused by transitions at $\mathrm{CpG}$ dinucle- otides; ${ }^{(7)}$ these transitions will provide an extra segment when ddTTP or ddATP are the terminators.

The sensitivity of mutation detection
TABLE 4 The Relationship between the Efficiency of ddF and Its Components

\begin{tabular}{lcccccc}
\hline & $\begin{array}{l}\mathrm{dd}^{ \pm} \text {and } \\
\mathrm{SSCP}^{+} \\
(\%)\end{array}$ & $\begin{array}{l}\mathrm{dd}^{0} \text { and } \\
\mathrm{SSCP}^{+} \\
(\%)\end{array}$ & $\begin{array}{l}\mathrm{dd}^{ \pm} \text {and } \\
\mathrm{SSCP}^{0} \\
(\%)\end{array}$ & $\begin{array}{l}\mathrm{dd}^{0} \text { and } \\
\mathrm{SSCP}^{\circ} \\
(\%)\end{array}$ & $\begin{array}{l}\text { Observed ddF } \\
\text { hemi/homozygote } \\
\text { sensitivity (\%) }\end{array}$ & $\begin{array}{l}\text { Estimated ddF } \\
\text { heterozygote } \\
\text { sensitivity (\%) }\end{array}$ \\
\hline $\mathrm{PA}, 23^{\circ} \mathrm{C}$ & 49 & 34 & 11 & 5 & 95 & 91 \\
$\mathrm{GA}, 23^{\circ} \mathrm{C}$ & 51 & 38 & 8 & 3 & 97 & 95 \\
$\mathrm{PA}, 8^{\circ} \mathrm{C}$ & 56 & 39 & 3 & 1 & 99 & 98 \\
$\mathrm{GA}, 8^{\circ} \mathrm{C}$ & 58 & 40 & 1 & 0 & 100 & 99.6 \\
\hline
\end{tabular}

Eighty-four single-base mutations were examined. The percentage of each of the four types of ddF patterns is shown. ( $\mathrm{dd}^{ \pm}$) Abnormal dideoxy component attributable to the presence or the absence of a band; $\left(\mathrm{dd}^{0}\right)$ no abnormality seen in the dideoxy component; $\left(\mathrm{SSCP}^{+}\right)$at least one segment in the SSCP component has an abnormal mobility; $\left(\mathrm{SSCP}^{0}\right)$ none of the segments show mobility alterations.

${ }^{\text {a }}$ Polyacrylamide (PA) and GeneAmp (GA) gels were electrophoresed at $23^{\circ} \mathrm{C}$ and $8^{\circ} \mathrm{C}$.

${ }^{b}$ The observed ddF efficiency was with hemizygous males containing mutations in the factor IX gene. Mutations associated with $\mathrm{dd}^{0} / S S C P^{0}$ are missed. A few samples were excluded from analysis because the SSCP component was not positive, but small changes in mobility could not be evaluated because neither adjacent lane had normal sequence. Thus, for PA and GA at $23^{\circ} \mathrm{C}, 79$ and 78 mutations were analyzed, respectively. In patients heterozygous for a sequence change, $\mathrm{dd}^{-} / \mathrm{SSCP}^{0}$ mutations (loss of a segment attributable to the mutation and no abnormal mobility relative to any SSCP segment) can also be missed (see text). To estimate the efficiency of ddF for detection of heterozygotes, it is assumed that all mutations of this type are missed and that ddATP (or ddTTP) is utilized to help maximize the number of extra bands in the dideoxy component produced by transitions at CpG. In our sample of 84 mutations, 15 lose a segment when ddA is the terminator. Thus, the efficiency of ddF for heterozygotes is $\mathrm{SSCP}^{0} \times\left(\mathrm{dd}^{0}+\mathrm{dd}^{-}\right)$. by ddF and SSCP was examined under different conditions. The samples were electrophoresed through polyacrylamide, MDE, or GeneAmp gels at either $23^{\circ} \mathrm{C}$ or $8^{\circ} \mathrm{C}$. The sensitivity of ddF was found to be high under all conditions tested. The efficiency of the SSCP component of the ddF pattern varied markedly. The SSCP component of ddF can be used to estimate the efficiency of conventional SSCP in which the mobility of a pair of complementary segments is analyzed (see Table 3 , footnotes). Low temperatures and the use of GeneAmp (or MDE) gels improve the efficiency of the SSCP component. In addition, $10 \%$ glycerol or an increased ratio of polyacrylamide to bisacrylamide $(50: 1)$ improve the average efficiency of polyacrylamide gels at $23^{\circ} \mathrm{C}$. However, GeneAmp gels at $8^{\circ} \mathrm{C}$ were found to be superior to all other conditions tested.

\section{Efficiency of SSCP}

The reported sensitivity of conventional SSCP varies dramatically. ${ }^{(1,8-14)}$ Our data illustrate that there are at least four underlying parameters that affect the SSCP efficiency. The specific mutation influences the efficiency in the SSCP component as illustrated in Table 2, Figure 3, and Figure 5A (see Materials and Methods for the difference between SSCP component sensitivity and conventional SSCP sensitivity). The most dramatic mutant-to-mutant variation in SSCP component efficiency occurred for polyacrylamide gels at $23^{\circ} \mathrm{C}$. The SSCP component efficiency is also a function of the primer used (Table 3). For polyacrylamide gels at $23^{\circ} \mathrm{C}$, the average efficiency of the SSCP component varied from $22 \%$ in primer $\mathrm{C}$ to $56 \%$ in primer $\mathrm{H}$. Third, segment size also affects SSCP component efficiency (Fig. 6B). For those samples analyzed with polyacrylamide gels at $23^{\circ} \mathrm{C}$, the average SSCP component efficiency decreased from $68 \%$ when the segments were $21-80$ bases to $34 \%$ when the segments were $160-240$ bases. Fourth, the position of the mutation relative to the $3^{\prime}$ end can affect the SSCP component efficiency. These results can explain the dramatic variation in the sensitivity of conventional SSCP from region to region and laboratory to laboratory.

We speculate that the sensitivity of one strand of SSCP for a given region 

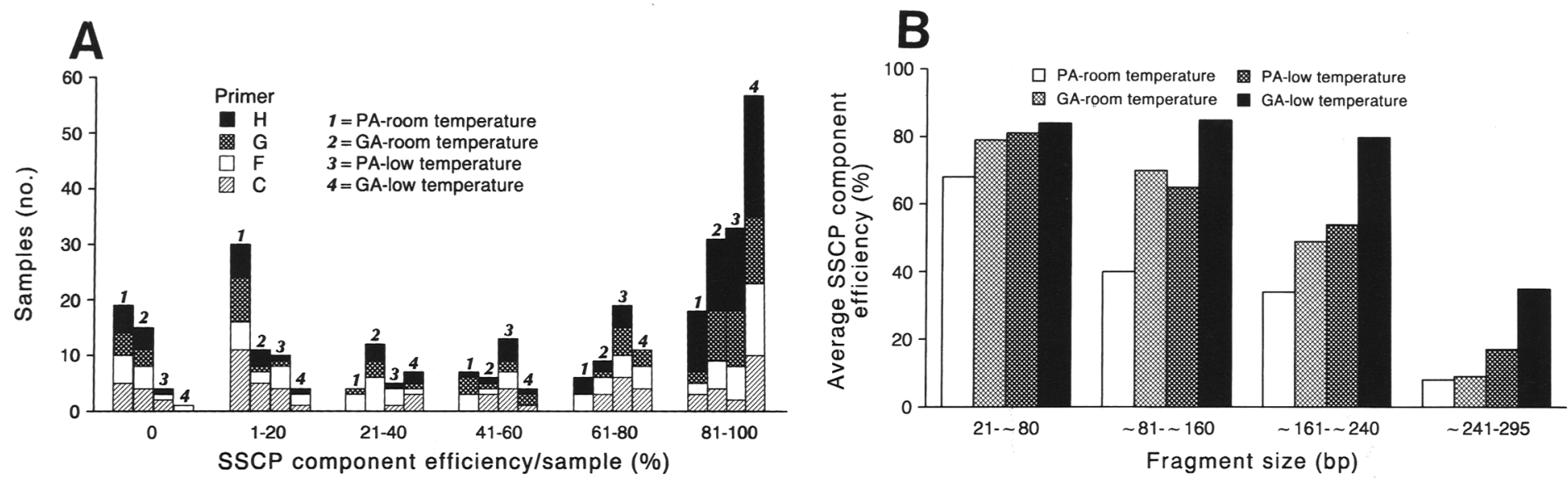

FIGURE 6 Distribution of SSCP component efficiency as a function of primer, gel matrix, temperature, and segment size. The SSCP component efficiency was determined for each sample. $(A)$ The number of samples within a given range of efficiencies is shown on the $y$-axis. The SSCP component efficiency per sample is shown for four primers and four gel conditions. (B) The segments in the SSCP component are divided into four size groups ranging from $21-80$ bases to $241-295$ bases. The average SSCP component efficiency for primers C, F, G, and H is plotted as a function of segment size for four electrophoresis conditions.

depends on the distribution of mobilities of single-base changes and the location of the normal sequence within that distribution (Fig. 8). For a 200-bp segment, there are 600 possible variants that differ by a single-base substitution. If these variants could be generated and electrophoresed under a given set of conditions, the mobility distribution could be determined. Although the distribution is unknown, it might be as- sumed that the distribution is Gaussian. If the mobility is plotted in units of bandwidths and the resolution is $\pm 1 / 2$ bandwidth, it is apparent that the sensitivity of SSCP will be less for a segment in which the mobility of the normal sequence is close to the mode (see point $\mathrm{A}$ ) in comparison with a normal sequence in which the mobility occupies position B. For the same segment electrophoresed under a second set of conditions, the

TABLE 5 Relationship between SSCP Efficiency and Mutation Type

\begin{tabular}{|c|c|c|c|c|c|c|}
\hline \multirow{3}{*}{$\begin{array}{l}\text { Mutation } \\
\text { type }\end{array}$} & \multirow{3}{*}{$\begin{array}{l}\text { Mutation } \\
\text { no. }^{\text {a }}\end{array}$} & \multirow{3}{*}{$\begin{array}{l}\text { Segment } \\
\text { no. }\end{array}$} & \multicolumn{4}{|c|}{ SSCP Efficiency $(\%)^{c}$} \\
\hline & & & \multicolumn{2}{|c|}{$23^{\circ} \mathrm{C}$} & \multicolumn{2}{|c|}{$8^{\circ} \mathrm{C}$} \\
\hline & & & PA & GA & PA & GA \\
\hline$\rightarrow \mathrm{T}$ & 4 & 134 & 19 & 66 & 43 & 72 \\
\hline$A \rightarrow G$ & 7 & 201 & 38 & 56 & 64 & 72 \\
\hline$\rightarrow \mathrm{C}$ & 4 & 46 & 26 & 38 & 76 & 89 \\
\hline$\rightarrow \mathrm{A}$ & 3 & 67 & 10 & 42 & 95 & 96 \\
\hline $\mathrm{T} \rightarrow \mathrm{G}$ & 3 & 119 & 46 & 80 & 71 & 86 \\
\hline$\rightarrow \mathrm{C}$ & 6 & 198 & 32 & 42 & 21 & 41 \\
\hline$\rightarrow \mathrm{A}$ & 14 & 356 & 56 & 76 & 74 & 97 \\
\hline $\mathrm{G} \rightarrow \mathrm{T}$ & 8 & 175 & 11 & 23 & 36 & 74 \\
\hline$\rightarrow \mathrm{C}$ & 4 & 142 & 65 & 77 & 79 & 89 \\
\hline$\rightarrow \mathrm{A}$ & 10 & 205 & 33 & 49 & 70 & 90 \\
\hline $\mathrm{C} \rightarrow \mathrm{T}$ & 17 & 541 & 28 & 47 & 53 & 77 \\
\hline$\rightarrow \mathrm{G}$ & 4 & 104 & 83 & 82 & 86 & 94 \\
\hline Transitions & 44 & 1306 & 38 & 55 & 55 & 76 \\
\hline Transversions & 40 & 962 & 38 & 59 & 65 & 87 \\
\hline Total & 84 & 2268 & 38 & 57 & 60 & 81 \\
\hline
\end{tabular}

SSCP efficiency and mutation type combine data from primers $C, F, G$, and $H$.

${ }^{a}$ The number of different mutations with a given mutation type.

'The total number of segments in the SSCP component.

'(PA) Polyacrylamide gel; (GA) GeneAmp gel.

TABLE 6 SSCP Component Efficiency as a Function of the Proximity of the Mutations from the 3' End of the Segment

\begin{tabular}{lcccc}
\hline & \multicolumn{4}{c}{$\begin{array}{c}\text { Number of segments 3' } \\
\text { from the mutation (\%) }\end{array}$} \\
\cline { 2 - 5 } Conditions & $1-3$ & $4-6$ & $7-9$ & all \\
\hline $\mathrm{PA}, 23^{\circ} \mathrm{C}$ & 55 & 43 & 37 & 38 \\
$\mathrm{GA}, 23^{\circ} \mathrm{C}$ & 64 & 61 & 57 & 57 \\
$\mathrm{PA}, 8^{\circ} \mathrm{C}$ & 83 & 75 & 69 & 60 \\
$\mathrm{GA}, 8^{\circ} \mathrm{C}$ & 85 & 84 & 86 & 81 \\
\hline
\end{tabular}

Data are from primers $C, F, G$, and $H$. Thus, for GeneAmp gels at $8^{\circ} \mathrm{C}, 85 \%$ of the segments 1-3 terminations from the mutation site had an altered mobility while only $55 \%$ occurred for $\mathrm{PA}$ at $23^{\circ} \mathrm{C}$.

${ }^{\text {aS }}$ egment number is calculated from the mutations. (1-3) The first three termination segments immediately to the $3^{\prime}$ end from the mutations; (4-6) the fourth, fifth, and sixth termination segments to the $3^{\prime}$ end from the mutation; (7-9) the seventh, eighth, and ninth segments to the $3^{\prime}$ end from the mutation. 


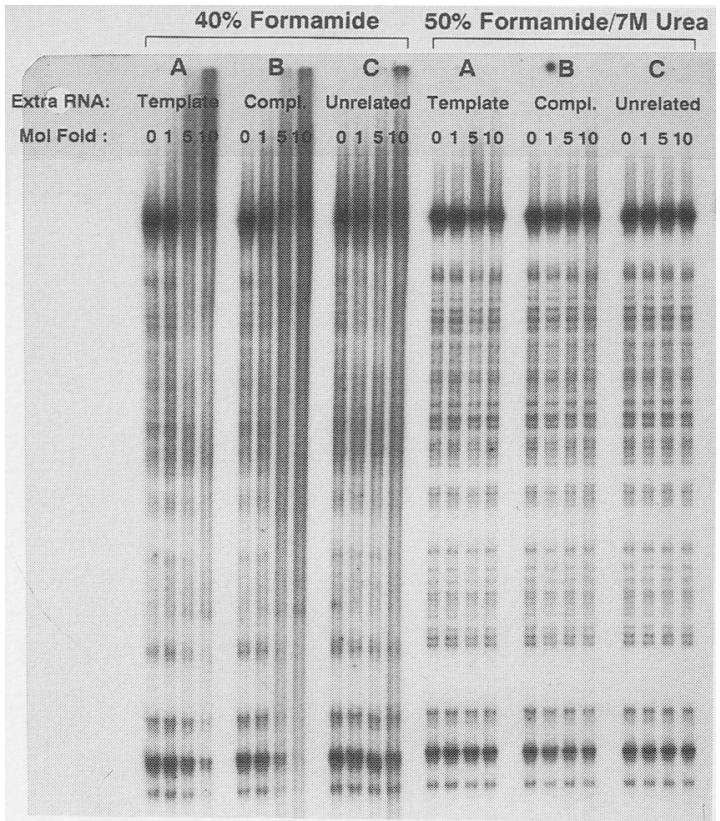

FICURE 7 Stop/loading buffer with 50\% formamide and $7 \mathrm{~m}$ urea inhibit smearing. A 789-bp fragment of the D1 receptor gene was amplified by primers I and J, and the termination reaction was performed with ddTTP. One microliter of the Sanger sequence reaction was added to $4 \mu \mathrm{l}$ of either $40 \%$ formamide or $50 \%$ formamide $/ 7 \mathrm{M}$ urea stop/loading buffer. Additional RNA was also added in the following amounts: 0-, 1-, 5-, and 10-fold more RNA was added in each group of four lanes. (Group $A$ ) Additional template RNA was added; (group $B$ ) complementary RNA was added; (group $C$ ) an unrelated 600-bp RNA was added (exons 2 and 3 from the human factor IX gene). (Mol Fold) The molar ratio of the added RNA relative to the normal amount of template RNA in the termination reaction. Samples were electrophoresed through $0.5 \times$ MDE gels at $8^{\circ} \mathrm{C}$. Prior to loading, the samples were boiled for $3 \mathrm{~min}$ and slowly cooled to $37^{\circ} \mathrm{C}$ within $30 \mathrm{~min}$.

\section{Does the Average Efficiency of the SSCP Component Reflect the Sensitivity of Conventional SSCP?}

The sensitivity of conventional SSCP is determined by the sensitivities of two complementary segments. The SSCP component efficiencies of ddF herein are based on the mobilities of $>2200$ segments for 84 different mutations. The higher the average efficiency of the SSCP component, the higher the average sen- sitivity of conventional SSCP. Our estimates of the sensitivity of conventional SSCP are lower than most previous estimates of sensitivity (for review, see Hayashi and Yandel). ${ }^{(11)}$ There may be a number of reasons for this, including the following: (1) Some unknown problem in our laboratory may result in suboptimal SSCP gels; (2) sensitivities are sometimes based on SSCP performed under two to four conditions while the present estimate is for SSCP under one condition; and (3) there may be a bias against publication of regions in which SSCP has a low sensitivity, that is, showing that a region has a sensitivity approaching $100 \%$ is relatively clear cut, whereas finding a low sensitivity leads to questions about optimal laboratory technique. This also decreases the probability of manuscript acceptance by inviting questions by reviewers on the accuracy of the biological conclusions obtained by the screening of the relevant regions with SSCP.

\section{Aids in Optimizing ddF}

$\mathrm{ddF}$ is a robust technique that has been used by many individuals in the laboratory to screen an aggregate of $>2 \mathrm{Mb}$ of human genomic sequence in the factor IX, the p53, and the dopamine D1, D2, D4, and D5 receptor genes. As with sequencing and conventional SSCP, some initial practice in ddF is required to obtain high-quality reproducible autoradiographs and to reliably distinguish mutations from artifact. On the basis of our

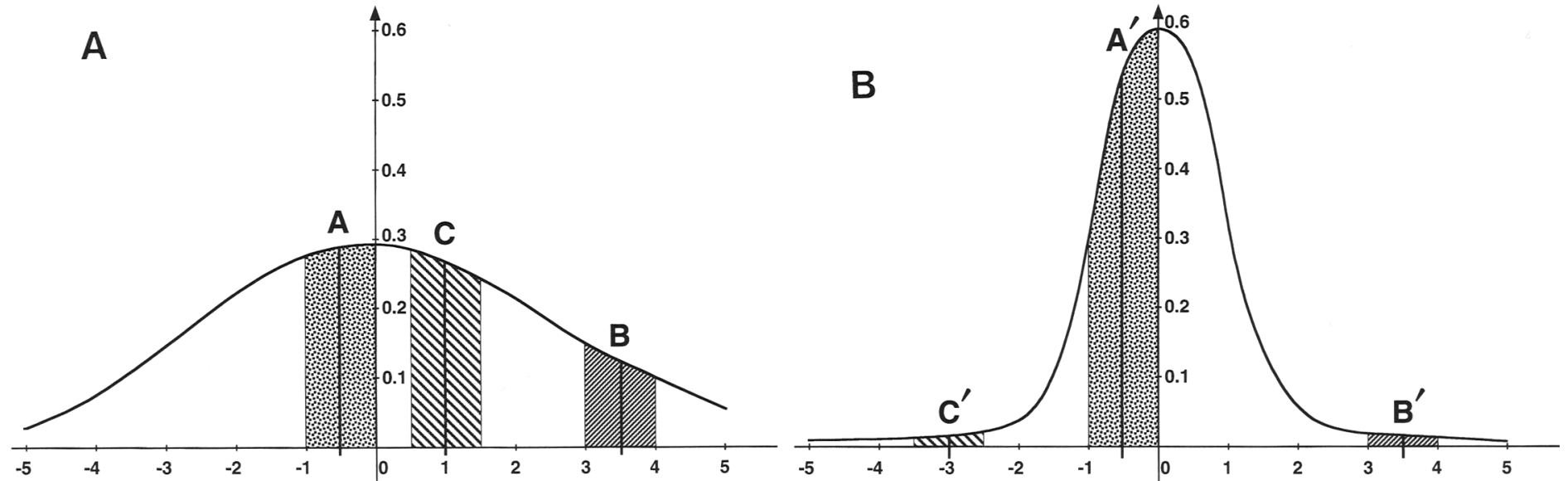

FIGURE 8 Schematic of how different distributions of mobilities and different locations of the wild-type sequence within the distribution affect the efficiency of detection of single-base changes. The units on the $x$-axis are in bandwidth lengths. The mobility is defined as the migration from the origin to the peak of the band divided by the electrophoresis period under certain conditions. The mobilities are relative to the most commonly observed mobility. The resolution of detection is $\pm 1 / 2$ bandwidth from the mobility of wild-type sequence. $(A)$ Three different wild-type mobilities are indicated by A, B, and C, respectively. (B) Electrophoresis of the same samples under a different set of hypothetical conditions. 
TABLE 7 Checklist for Achieving Technically Superior ddF with High Efficiency and Specificity

1. For optimal gels, perform a pilot sequencing reaction electrophoresed through a standard denaturing gel to choose a ddNTP that is likely to give good separation between the termination segments and to determine the amount of transcripts to utilize to obtain a good signal with ddF after autoradiography for 12-36 hr.

2. Process multiple samples $(>10)$ of the same region to minimize confusion between mutations producing subtle alterations and the normal range of sample variation.

3. When a substantial fraction of samples are expected to have a mutation, process a sufficient number of control samples so that at least one of the two adjacent lanes is very likely to contain a normal sequence.

4. Generate similar concentrations of PCR-amplified DNA for each sample; if concentrations differ, adjust the volume so that approximately equivalent amounts of DNA template are added to the transcription reaction.

5. After the termination reaction, use a stop buffer with sufficient amounts of denaturing strength (see text).

6. Use square-well combs rather than shark-tooth combs.

7. Position the fan to provide even cooling.

8. To avoid false-negative samples attributable to subtle alterations in the SSCP component, reelectrophorese samples in orphan lanes, i.e., lanes in which neither adjacent sequence is normal.

9. Don't score a sample as positive if the intensity of the signal fades out as the segment gets larger; this pattern is attributable to a poor termination reaction producing multiple nonspecific termination products by AMV reverse transcriptase or whatever polymerase is being used. Expose autoradiographs long enough to achieve a strong signal; if a sample seems to contain added termination segments in addition to all of the normal segments and close inspection reveals faint normal segments at that exact mobility, the pattern is attributable to a suboptimal ddF Sanger reaction and not a mutation. $^{\mathrm{a}}$

10. If even one segment of the SSCP component is subtly but clearly different from flanking adjacent normal segments, the sample should be assumed to contain a mutation until high-quality sequence in both directions fails to reveal a mutation. ${ }^{\mathrm{b}}$ The sequencing reactions should examine all base pairs capable of resulting in an abnormal ddF.

aUsually these samples are attributable to suboptimal termination reactions that are more subtle than the ones mentioned above; on inspection, the intensity of the upper segments is almost always found to decrease relative to optimal termination reactions of normal sequence.

bIn our experience, band compressions, shadow bands, or mutations that occur below the first segment clearly resolved on the sequencing gel have resulted in initial false-negative sequencing gels. Confidence that a given pattern does represent a sequence change prompted further investigation, which revealed the sequence change.

experience, a ddF checklist is offered to facilitate the optimal quantitative detection of mutations with few, if any, falsepositive samples (Table 7).

In conclusion, multiple parameters affecting the sensitivity of SSCP and ddF have been defined. SSCP, when performed under one condition, is about two times faster than ddF, but ddF consistently has a higher sensitivity of mutation detection. For situations in which it is important to detect the presence of essentially all mutations, ddF is the preferred method. ddF has additional benefits in some contexts, that is, spurious PCR amplification products are essentially never a problem, because (1) the fingerprints are generated by a nested termination reaction primer, (2) large segments can be screened conveniently by synthesis of termination reaction primers every $150-250 \mathrm{bp}$, and (3) the location of the mutation within the region can be estimated.

\section{ACKNOWLEDGMENTS}

We gratefully acknowledge Robert Molinari and Ann Bailey, of AT Biochem (Malvern, Pennsylvania) for helpful discussions and for providing proprietary gel matrices for analyses. We thank Mary Johnson for expert secretarial assistance.

\section{NOTED ADDED IN PROOF}

For maximum ddF sensitivity, it is critical that a normal sequence be in one of the adjacent lanes. A small, but distinguishable, misalignment of even one band in a sample and adjacent normal control is excellent evidence for the presence of a mutation if the bands above and below align perfectly.

\section{REFERENCES}

1. Sarkar, G., H. Yoon, and S.S. Sommer 1992. Dideoxy fingerprinting (ddF): A rapid and efficient screen for the presence of mutations. Genomics 13: 441-443.

2. Stoflet, E.S., D.D. Koeberl, G. Sarkar, and S.S. Sommer. 1988. Genomic amplification with transcript sequencing. Science 239: 491-494.

3. Sommer, S.S. and E.L. Vielhaber. 1994. Phage promoter-based methods for sequencing and screening for mutations. In The polymerase chain reaction (ed. K. Mullis, F. Ferre, and R.A. Gibbs), pp. 214-221. Birkhauser, Boston, MA.

4. Sommer, S.S., G. Sarkar, D.D. Koeberl, C.D.K. Bottema, J. Buerstedde, D.B. Schowalter, and J.D. Cassady. 1990. Direct sequencing with the aid of phage promoters. In PCR protocols: $A$ guide to methods and applications (ed. M.A. Innis, D.H. Gelfand, J.J. Sninsky, and T.J. White), pp. 197-205. Academic Press, New York.

5. Sarkar, G., D.D. Koeberl, and S.S. Sommer. 1990. Direct sequencing of the activation peptide and the catalytic domain of the factor IX genes of six species. Genomics 6: 133-143.

6. Yoshitake, S., B.G. Schach, D.C. Foster, E.W. Davie, and K. Kurachi. 1985. Nucleotide sequence of the gene for human factor IX (anti-hemophilic factor B). Biochemistry 24: 3736-3750.

7. Cooper, D.N. and M. Krawczak. 1993. Human gene mutation Bios Scientific Publishers, Oxford, England.

8. Sheffield, V.C., J.S. Beck, A.E. Kwitek, D.W. Sandstrom, and E.M. Stone. 1993. The sensitivity of single-strand conformation polymorphism analysis for the detection of single base substitutions. Genomics 16: 325-332.

9. Michaud, J., L.C. Brody, G. Steel, G. Fontaine, L.S. Martin, D. Valle, and G. Mitchell. 1992. Strand-separating conformational polymorphism analysis: Efficacy of detection of point mutations in the human ornithine $\delta$-aminotransferase gene. Genomics 13: 389-394.

10. Hongo, T., G.S. Buzard, R.J. Calvert, and C.M. Weghorst. 1993. "Cold SSCP": A simple, rapid and non-radioactive method for optimized single-strand conformation polymorphism analyses. $\mathrm{Nu}$ cleic Acids Res. 21: 3637-3642.

11. Hayashi, K. and D.W. Yandell. 1993. How sensitive is PCR-SSCP? Hum. Mutat. 2: 338-346. 
12. Glavac, D. and M. Dean. 1993. Optimization of the single-strand conformation polymorphism (SSCP) technique for detection of point mutations. Hum. Mutat. 2: 404-414.

13. Takahashi-Fujii, A., Y. Ishino, A. Shimada, and I. Kato. 1993. Practical application of fluorescence-based image analyzer for PCR single-stranded conformation polymorphism analysis used in detection of multiple point mutations. PCR Methods Applic. 2: 323-327.

14. Sarkar, G., H. Yoon, and S.S. Sommer. 1992. Screening for mutations by RNA single-strand conformation polymorphism (rSSCP): Comparison with DNASSCP. Nucleic Acids Res. 20: 871-878.

Received April 27, 1994; accepted in revised form July 6, 1994.

.




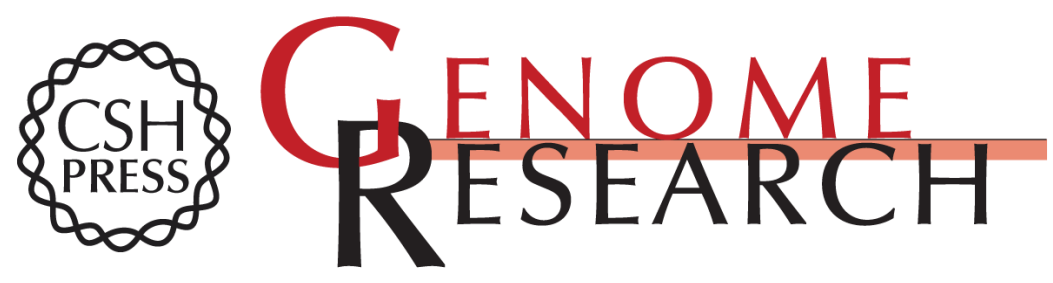

\section{Parameters affecting the sensitivities of dideoxy fingerprinting and SSCP.}

Q Liu and S S Sommer

Genome Res. 1994 4: 97-108

References This article cites 11 articles, 1 of which can be accessed free at: http://genome.cshlp.org/content/4/2/97.full.html\#ref-list-1

\section{License}

Email Alerting Service

Receive free email alerts when new articles cite this article - sign up in the box at the top right corner of the article or click here.

\section{Affordable, Accurate Sequencing.}

To subscribe to Genome Research go to:

https://genome.cshlp.org/subscriptions 